\title{
Influence of Electric Characteristics of Inhomogeneous Lithosphere on Excitation and Propagation of Seismogenic Electromagnetic Emissions
}

\author{
Yu.B.Bashkuev", D.G.Buyanova, M.G. Dembelov, V.B.Khaptanov, I.B.Naguslaeva, V.R.Advokatov \\ Institute of Physical Materials Science of the Siberian Branch of the Russian Academy of Sciences, 670047, Ulan - Ude, Russia \\ *Corresponding Author: buddich@mail.ru
}

Copyright (C) 2013 Horizon Research Publishing All rights reserved.

\begin{abstract}
In the paper the approach based on considerable non-uniformity of electric properties of lithosphere both by depth and by area is developed. Geoelectric sections (GES) of various types of continental lithosphere (rift hollows, crystalline massif, permafrost) to large depths are examined. The substantiation of models of the lithosphere electric conductivity in seismically active and stable areas is considered. The main attention is given to areas of crystalline massif and zones of geoelectric non-uniformities (tectonic faults) attributed to seismic generating structures. The GES of seismoactive area (to the depth of about $60 \mathrm{~km}$, up to 13-15 layers of GES) are studied on an example of the Baikal Rift Zone (BRZ).
\end{abstract}

Keywords Lithosphere, Electromagnetic Emissions, Tectonic Faults

\section{Introduction}

In the last 10-15 years, a new research direction of geophysics - seismoelectromagnetism [1-6] which includes a high-resolution probing of inhomogeneous medium and geophysical monitoring of seismoelectromagnetic emissions in the ULF - VLF - LF bands was formed. Researches in this direction are carried out in Japan, USA, China, Greece, Italy, France, Mexico, India and some other countries. In Russia the high seismic activity is observed in Kamchatka, Baikal rift zone, Altai and Caucasus. An important part of seismoelectromagnetism is the study of the electrical properties (conductivity $\sigma$ and permittivity $\varepsilon$ ) crustal seismic areas. This is due to the fact that earthquakes as pulsed mechanical processes always take place in the Earth's crust. The literature review showed that the non-uniform distributions of the electrical properties of underlying environment in the seismically active Baikal rift zone are not fully investigated. In this paper the electrical properties of heterogeneous natural environments are considered from the point of view of the interaction of medium and electromagnetic waves with the use of the theory of propagation electromagnetic waves over impedance structures. The most interesting from this point of view are the fault zone in the crust, which have a length of up to hundreds of miles and a width of several meters to tens of kilometers. Analysis of published data showed that geophysical fault model is not created. Therefore, one of the objects of investigation is fault zones in the Earth crust. Similar studies in Russia and other countries in this area were not carried out. Thus, the subject is relevant and is in line with global research priorities in the seismoelectromagnetism area.

As a rule, methods of generation and propagation of seismogenic electromagnetic emissions offered by many authors [7,8] consider the semi-conducting homogeneous medium. This is a big simplification of the real structure of the Earth crust. Now inhomogeneous distribution of electromagnetic properties of lithosphere is not well investigated. In the paper a method of approach is developed which is based on taking into account in particular the essential inhomogeneity of electrical properties of lithosphere in the calculating models with both the depth and the square distribution.

We believe lithosphere is a silicate covering of Earth about $100 \mathrm{~km}$ thick. The lithosphere includes crust and mantle and embodies hard layers that are above asthenosphere. The thickness of the lithosphere changes from $400 \mathrm{~km}$ in some continent of regions to first kilometers on middle oceanic ridges.

Electromagnetic methods give important and independent information concerning Earth subsurface structure. At present the magnetic-telluric sounding (MTS) is the only method that provides a necessary and sufficient completeness of investigations $[9,10]$.

Terrestrial rocks are nonmagnetic or low magnetic in most cases from the point of view of electromagnetic characteristics. Resistivity $\rho$ and dielectric permeability $\varepsilon$ are changed in wide limits depending on mineral composition, 
porosity, and content of water solutions and bedding conditions (pressure, temperature and so on) [11].

Earth crust inhomogeneities have an effect on its electric and seismic characteristics. Such parameters as electrical conductivity, velocity and absorption of seismic waves depend on availability of layers and zones that are saturated by fluids, mainly by water, in the Earth crust. Metamorphic processes that proceed in the Earth crust with fluids participation have certain influence on seismic activity. The article aim is to determine the electrical properties of the underlying medium of the Baikal Rift Zone and the assessment of their impact on the propagation of broadband electromagnetic emissions from the radio measurement data and modeling.

\section{Materials and Methods}

Conception of electrical stratification of consolidated Earth crust of continents was developed as a result of deep electromagnetic investigations of last years [9-22]. An upper part of the Earth crust from crystalline foundation surface to the depth of $10-20 \mathrm{~km}$ is high-resistive medium where extensive and relatively narrow zones with a high conductivity can be found. As a rule, resistivity of the deeper layers does not exceed a few hundred $\mathrm{Ohm} \cdot \mathrm{m}$. An upper part of the consolidated continent crust is characterized by very high background resistivity. For example, values of resistivities of upper part of consolidated crust on the Kola Peninsula and in Karelya are equal to $10^{4}-10^{5} \mathrm{Ohm} \cdot \mathrm{m}$ and more. In the central part of the Canadian Shield results of interpretation show that resistivity is equal to 140 thousands $\mathrm{Ohm} \cdot \mathrm{m}$ in the top 5 kilometers of geoelectrical section. As a result of inverse task of vertical electric sounding (VES) on African Craton a value of resistivity of upper part of the crust was found. The value that is equal to $8 \cdot 10^{4} \mathrm{Ohm} \cdot \mathrm{m}$ is close to data on the Baltic and the Canadian Shields.

The most important result of geoelectrics of last years is a disclosure of electric stratification of the Earth crust. If the upper part of the Earth crust is characterized by high resistivity (as a rule, a tens of thousands of Ohm.m), then the resistivity on the depth of more than 15-20 kilometers decreases by $2-3$ orders. This considerable decrease in resistivity (sometimes up to $10 \mathrm{Ohm} \cdot \mathrm{m}$ ) encompasses territories with the size of hundred kilometers. The conducting lower crust is situated between two high-resistive layers: upper part of the Earth crust and mantle (Figure 1).

The achieved level of study by methods of deep geoelectrics allows to create "many-storied" models of distribution of conductors in the crust and mantle united in the complex current systems in the row regions with a usage of MTS, VES, DES data [10, 12, 13, 17, 19]. Let us give a review of some typical examples. Figure 2 shows two-dimensional geoelectrical model of the Baikal rift zone created by M.N.Berdichevsky, L.L.Van'yan, and A.V.Koshurnikov [12].

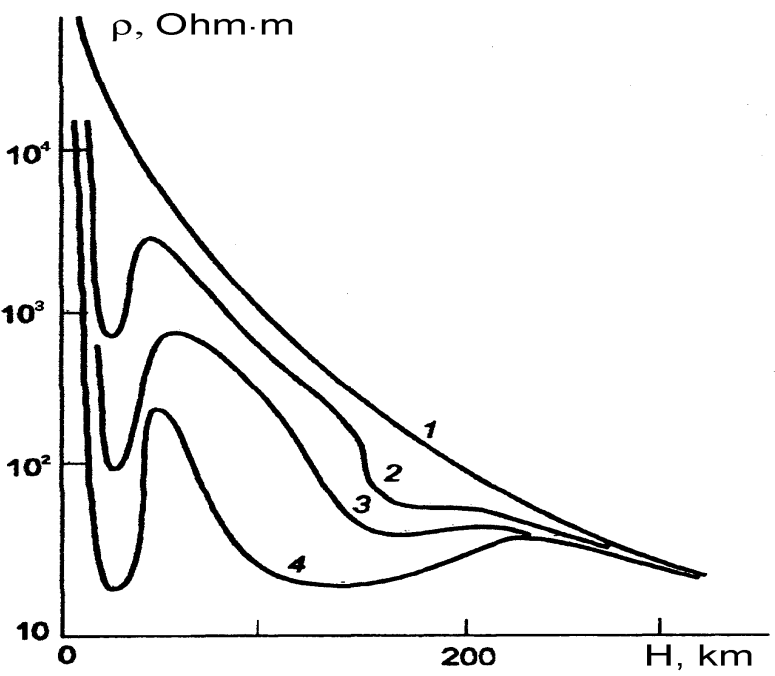

Figure 1. The summary geoelectric section of the Earth crust and upper mantle of continents [9]. Sections: 1- standard "cold" $\left(40-45 \mathrm{~mW} / \mathrm{m}^{2}\right) ; 2$ and 3 - intermediate; 4 - "warm" $\left(90 \mathrm{~mW} / \mathrm{m}^{2}\right)$.

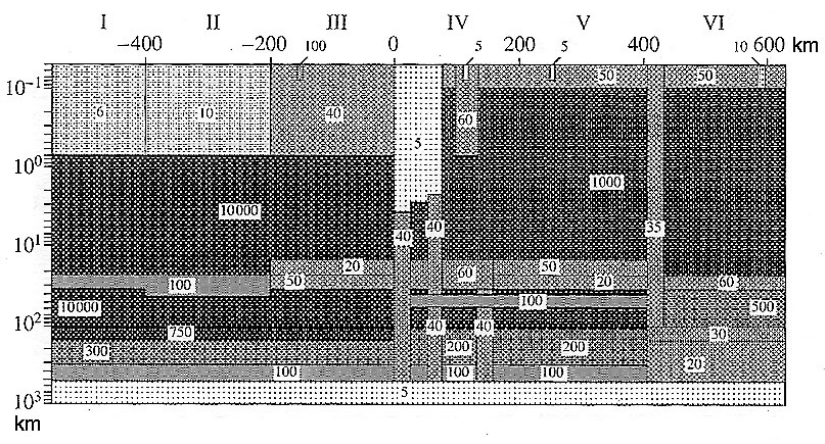

Figure 2. Deep geoelectric section of the Baikal rift zone [12]. Roman digits - zones numbers; Arabian digits - resistivity, Ohm.

Main elements of the model are:

1) Inhomogeneous sediment cover differentiated according to electric prospecting data;

2) Upper fragile part of the consolidated earth crust with high resistivity $10^{4}-10^{6} \mathrm{Ohm} \cdot \mathrm{m}$;

3) Uninterrupted conducting layer in the middle crust with resistivity that decreases from $200 \mathrm{Ohm} \cdot \mathrm{m}$ on the Siberian platform to $15-30 \mathrm{Ohm} \cdot \mathrm{m}$ in the rift zone and $60 \mathrm{Ohm} \cdot \mathrm{m}$ in the South-East Transbaikalia;

4) Vertical conducting zones (35-60 Ohm.m), that divide the upper crust;

5) Asymmetric asthenosphere with resistivity that changes from 100-200 $\mathrm{Ohm} \cdot \mathrm{m}$ on the Northwest to 20-30 Ohm.m in the Southeast.

Conducting channels are connected with known faults: Obruchev fault, Barguzin fault, Main Mongol-Ohotsk fault. They might be interrupted as faulted fluid saturated zones in the upper and middle crust. They connect sediment cover with deep crustal and mantle conductors. In the middle part of the Earth crust of the Baikal rift zone (about 15-30 km deep) resistivity decreases on two orders and reaches 20-100 $\mathrm{Ohm} \cdot \mathrm{m}$. 
Figure 3 shows a similar geoelectric model for seismoactive Tien-Shan region $(60 \mathrm{~km}$ to the East from Alma-Ata). The model was created by Yu.A.Trapeznikov, M.N.Berdichevsky and other [13].

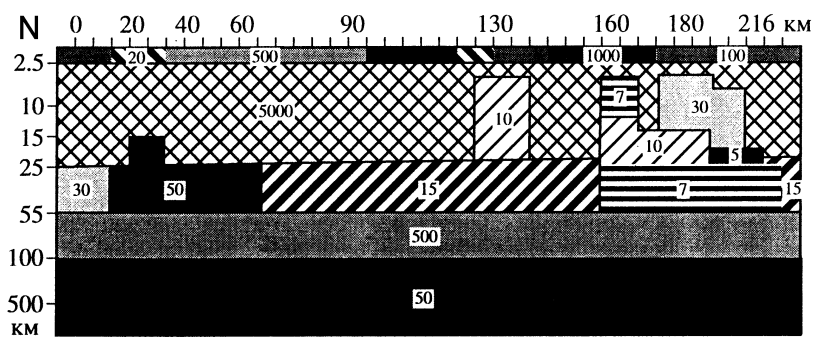

Figure 3. Geoelectric section on the N-S Tian-Shan profile [13]. Resistivities of model elements are marked in Ohm.m into it.

The model consists of:

1) Inhomogeneous surface sediment layer imitating intermountain depressions (10-100 Ohm $\cdot \mathrm{m})$;

2) High-resistive upper crust $(5000 \mathrm{Ohm} \cdot \mathrm{m})$ that contains local conducting inclusions (subvertical fluid-saturated faults);

3) Conducting layer in the low crust $(25-55 \mathrm{~km})$ with a resistivity that increases in the north direction from 5-15 Ohm $\cdot \mathrm{m}$ to $30-50 \mathrm{Ohm} \cdot \mathrm{m}$;

4) High-resistive mantle $(500 \mathrm{Ohm} \cdot \mathrm{m})$;

5) Low-resistive mantle $(50 \mathrm{Ohm} \cdot \mathrm{m})$.

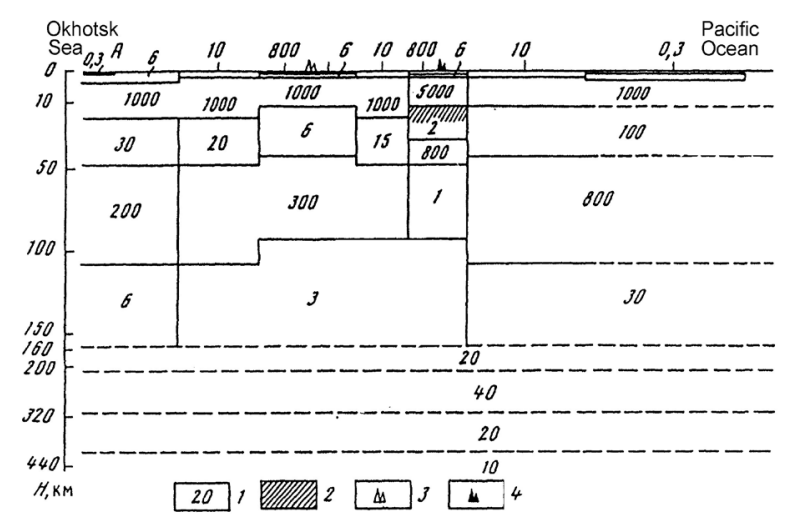

Figure 4. Deep geoelectric section of Kamchatka peninsula [19]. 1 resistivity in Ohm.m; 2 - low velocities zone; 3 - irruption zone; 4 - modern volcanism zone.

The upper crust contains conducting zones in the southern part of profile in a region of two big faults. These zones branch off from low-crustal conductor up to 3-8 kilometers deep. Resistivities of these zones vary from 5 to $30 \mathrm{Ohm} \cdot \mathrm{m}$. Low mantle resistivities begin from a depth of 100 kilometers.

Figure 4 shows the deep geoelectric section of seismoactive Kamchatka constructed by Yu.F.Moroz [19].

A high resistivity of fundament $10^{4}-10^{5} \mathrm{Ohm} \cdot \mathrm{m}$ on the depth of $0.5-10$ kilometers is defined for seismostable regions as well, in particular, for Belorussia [10]. Resistivity of the section decreases roughly on the depth of 10-11 kilometers achieving 200-300 Ohm.m. In this time the conducting crustal layer might be anisotropic.

According to MTS data sufficiently reliable geoelectric models of seismoactive regions of Baikal rift zone, Tian-Shan and Kamchatka were constructed. These models contain inhomogeneous conducting layer in the low part of the Earth crust and sub-vertical conducting zones in the upper crust $[12,13,19]$. Low resistivities are correlated with low velocities and a high absorption of seismic waves. This fact allows to tell about fluid nature of crustal conductors. It is important that sub-vertical conducting zones in the upper crust conform to known deep faults. Most of earthquakes have a propensity to these zones.

Geoelectrical inhomogeneity of the crust results in complex trajectories of electromagnetic energy stream because of great contrast of geoelectric borders. Conducting horizons and vertical conductive zones limiting high resistive layer of the upper part of the Earth crust are wave-guide, reflective and absorbing areas. Decrease or increase of electrical borders contrasts is possible when seismic events prepare to occur.

Geoelectrical construction of separate areas of the Earth crust promotes appearance electromagnetic wave-guides and low-quality resonators in high resistive layers of the Earth crust. Important seismoelectromagnetic problem is to investigate and map wave-guides, areas of their outcrops on the Earth surface (lithosphere "windows"), shady areas, reflection and absorption zones.

I.G.Kissin and A.I.Ruzaikin [14,15] compared spatial location of seismoactive and electric conducting zones in the Earth crust. The comparison showed that, as a rule, hypocenters are situated over regional conducting layer. The largest concentration of hypocenters was registered mainly close to contacts between blocks with a contrast difference of electric conductivity and on areas with a high overfall of depths of conducting layer. The commonness of location of conducting and low-velocity (wave guide) layers indicates their fluid nature.

Thus, the works of Russian geophysicists [9-21] established that common peculiarities of hypocenters in geoelectrical section of the Earth crust exist. Almost all hypocenters are situated over conducting horizon with rare exception. They are located within the high-resistive layer and projections of conducting bodies penetrated into upper crust. These bodies are often oriented in the sub-vertical direction.

The disposition of hypocenters according to the indicated geoelectrical inhomogeneities of the Earth crust is noted in a number of seismoactive regions. So, foci of a strong earthquake in the Nanpin region (Northern China) are related mostly to the high-resistive layer bedding on depth of 10-30 $\mathrm{km}$ between two electric conducting layers. Decrease of the apparent resistivity on depths of focus zone more that on $70 \%$ was indicated within this region after earthquake of 1976. This fact is connected with an increase of water saturation of rock due to dehydration of muscovite-quartz thickness [14]. 
The prevailing number of earthquake centers $(65-75 \%)$ is related to the upper 10-kilometer part of the Earth crust in many seismoactive regions [14]. Strong earthquake centers situate on big depths (15-40 km and more). Almost all hypocenters are related to high-resistive layers bedding above conducting horizon. Let us pay particular attention to this and let us consider the geoelectrical section of the upper part in many regions of the Earth. These massifs occupy considerable areas reaching a hundred kilometers in length and in width. Let us name these areas as lithosphere "windows" $[7,30]$.

\section{Results}

The results of geoelectrical mapping by means of air-variant method in VLF range of radiowaves, radio-impedance sounding in ELF-VLF-LF-MF ranges and VES [20] give sufficiently detailed information concerning surface electric conductivity.

Figure 5 shows VES curves obtained on Konkudery-Ma makan granitoid massif. The apparent resistivity $\rho_{\mathrm{a}}$ is equal to about 115 thousands $\mathrm{Ohm} \cdot \mathrm{m}$ even at small base line $\mathrm{AB} / 2$. The resistivity at a big base line does not fall down to less than 20 thousands $\mathrm{Ohm} \cdot \mathrm{m}$. Statistical estimations of resistivity of crystal rocks of the Baikal rift zone according to VES data are shown in the table 1 [22].

We can judge about a character of the upper part of geoelectrical section (GES) with the help of Figure 6 that shows spatial distribution of the effective resistivity $\rho_{\sim}$ on the frequency of $22.3 \mathrm{kHz}$ on the profile of $30 \mathrm{~km}$ of length, that passes within the Konkudery-Mamakan granitoid massif. The profile was created according to radioimpedance data from an AN-2 aircraft [20].

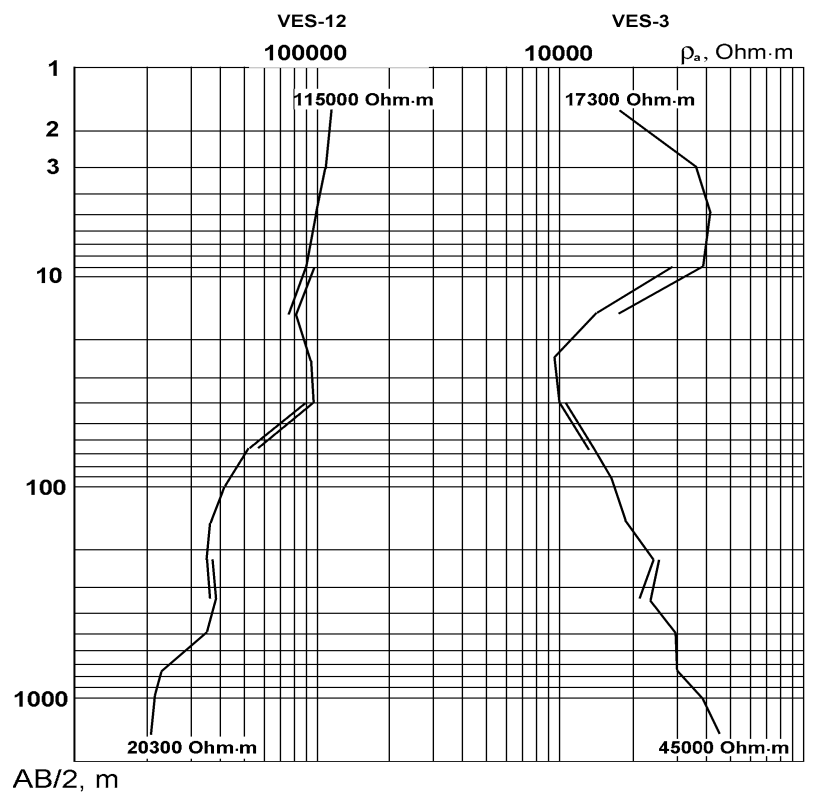

Figure 5. Apparent resistivity $\rho_{\mathrm{a}}$ under conditions of VES results with $\mathrm{AB} / 2=1500 \mathrm{~m}$ extended base lines on the Konkudery-Mamakan granitoid massif.

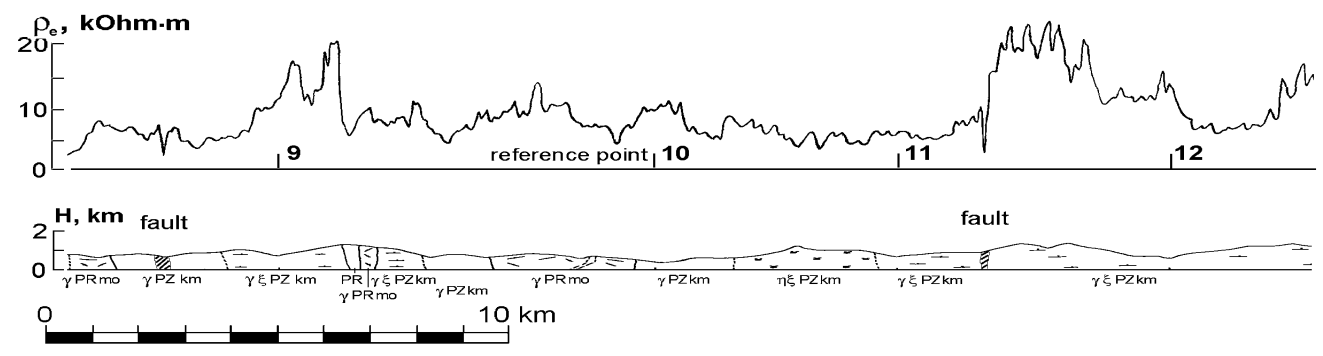

Figure 6. Results of $\rho_{\sim}$ definition on the frequency of $22.3 \mathrm{kHz}$ along the profile of $30 \mathrm{~km}$ length (Konkudery-Mamakan massif).

Table 1. Statistical properties of resistivity of crystal rocks of the Baikal rift zone

\begin{tabular}{|c|c|c|c|}
\hline Complex of rocks & $\begin{array}{c}\text { Average geometric value of } \rho \\
\text { Ohm·m }\end{array}$ & Standard deviation lg $\rho$ & $\rho_{\max } / \rho_{\min }$, Ohm $\cdot \mathrm{m}$ \\
\hline $\begin{array}{c}\text { Sub-volcanic formation and } \\
\text { gabbroids PR }\end{array}$ & 11800 & 0.13 & $23000 / 3500$ \\
\hline Methamorphic rocks AR & 5900 & 0.25 & $11000 / 1000$ \\
\hline Alcaline-earth granitoids PZ-MZ & 2200 & 0.18 & $6000 / 900$ \\
\hline
\end{tabular}

Table 2. Results of interpretation radioimpedance soundings

\begin{tabular}{|c|c|c|c|c|c|c|}
\hline \multirow{2}{*}{ Observation sites } & \multicolumn{6}{|c|}{ GES parameters: $\rho_{\mathrm{i}}, \mathrm{Ohm} \cdot \mathrm{m} ; h_{\mathrm{i}}, \mathrm{m}$} \\
\cline { 2 - 7 } & $\rho_{1}$ & $h_{1}$ & $\rho_{2}$ & $h_{2}$ & $\rho_{3}$ & $h_{3}$ \\
\hline Buluktyn- Jalga & 240 & 54 & 2000 & 2600 & 93000 & $\infty$ \\
\hline Maila & 250 & 65 & 7600 & 5800 & 153000 & $\infty$ \\
\hline Angir 2 & 350 & 50 & 12000 & 4100 & 121000 & $\infty$ \\
\hline Mokovka & 130 & 15 & 1600 & 1900 & 105000 & $\infty$ \\
\hline Megdelgen & 350 & 70 & 1100 & 2000 & 105000 & $\infty$ \\
\hline Lake & 720 & 146 & 5700 & 3900 & 118000 & $\infty$ \\
\hline All points & 500 & 88 & 2400 & 2600 & 127000 & $\infty$ \\
\hline
\end{tabular}


The mountain terrain is characterized on the whole by dependence of geoelectrical conditions from relief. As a rule, low areas (river valley and hollows) have lower resistivities of rocks. But mountains are formed by monolith rocks with a high resistivity. Effective resistivity $\rho_{\sim}$ tends to increase in the whole when relative height increases. The difference of mountain ridges and hollows is reflected according to geological composition in values of effective resistivity $\rho_{\sim}$ the $\rho_{\sim}$ minimal values of mountain ridges are closely with the $\rho_{\sim}$ maximal values of hollows. The form of graphics for $\rho_{\sim}$ in hollows is smoothed with a small amplitude of change of $\rho_{\sim}$ in hollows is smoothed with a small amplitude of change of $\rho_{\sim}$. The form in the mountains is broken with a big amplitude of change of $\rho_{\sim}$ in hollows is smoothed with a small amplitude of change of $\rho_{\sim}$. The form in the mountains is broken with big amplitude of change of $\rho_{\sim}$. Minimal values of $\rho_{\sim}$ correspond to contact's zones, tectonic breaches, rivers' hollows with considerable thickness of loose sediments.

As a result of VLF radio-impedance profiling from aircraft board using the fields of NDT and NWC radio stations on the area of 120 thousand $\mathrm{km}^{2}$ a coincidence between electric boundaries of different mountain rock complexes (granitoids, Cambrian, Jurassic adjournments etc.) and geological boundaries is found. A considerable difference in electric resistivity of monolithic crystalline rocks and tectonic faults' zones is established. The dimensions and electric contrasts of electric resisitivity for the fault area of the large crystalline massif are determined.

As a rule, the geoelectric section of the crystal massifs is of a type as $\rho_{1}<\rho_{2}<\rho_{3}$ type. Like that, the next GES parameters (Table 2) were obtained in the southern part of the Baikal rift according to the data of radio-impedance sounding in the ELF range (field of "Zeus" radio station).

As shown, resistivities in the first hundred $\mathrm{Ohm} \cdot \mathrm{m}$ are typical for the top part of the section. The resistivity increases up to thousands of $\mathrm{Ohm} \cdot \mathrm{m}$ on a depth of 50-150 meters. Then, the resistivity increases up to tens and hundreds of thousands $\mathrm{Ohm} \cdot \mathrm{m}$ according to ELF radio-impedance sounding data. Results of definition of $\rho_{\sim}$ showed that $\rho_{\mathrm{ELF}}>\rho_{\mathrm{VHF}}$ for granitoid massifs.

In this time its ratio $\mathrm{k}=\rho_{\mathrm{ELF}} / \rho_{\mathrm{VHF}}$ is changed within 1.2-8.4 limits with a most possible value as $3-5$. Thus, the definition of effective resistivity in the VLF range from an aircraft surveys data allows to forecast the resistivity of the monolith granitoid thickness in the ELF range. VLF range mapping from the aircraft allows to define effectively the areas with a high resistivity of crust - lithosphere electromagnetic "windows".

Dielectric permeability $\varepsilon$ of layer-heterogeneous medium brings the considerable contribution already in the ranges of VLF-MF at excitation and propagation of the seismogenic electromagnetic emissions in low-conducted crystal rocks.

In contrast to resistivity $\rho$, the relative dielectric permeability $\varepsilon$ is changed within more narrow limits and is equal to 10 for most of rocks in average. For erupted rocks $\varepsilon$ is not more than 20 , for acid rocks $\varepsilon$ is equal to 4-9, for main rocks $\varepsilon$ is equal to 7-13 and for ultra main $\varepsilon$ is equal to 8-20.

Table 3 shows frequencies (in $\mathrm{kHz}$ ) when conductivity currents are equal to displacement currents $(60 \lambda \sigma=\varepsilon)$.

Table 3. Frequencies, when conductivity currents are equal to displacement currents

\begin{tabular}{|c|c|c|c|c|c|}
\hline$\rho$, Ohm.m / $\varepsilon$, rel.units & 5 & 10 & 20 & 30 & 40 \\
\hline $10^{3}$ & 3600 & 1800 & 900 & 600 & 60 \\
\hline $10^{4}$ & 360 & 180 & 90 & 6 & 4,5 \\
\hline $10^{5}$ & 36 & 18 & 9 & 0,6 & 0,45 \\
\hline $10^{6}$ & 3,6 & 1,8 & 0,9 & 0,06 & 0,045 \\
\hline $10^{7}$ & 0,36 & 0,18 & 0,09 & 0 \\
\hline
\end{tabular}
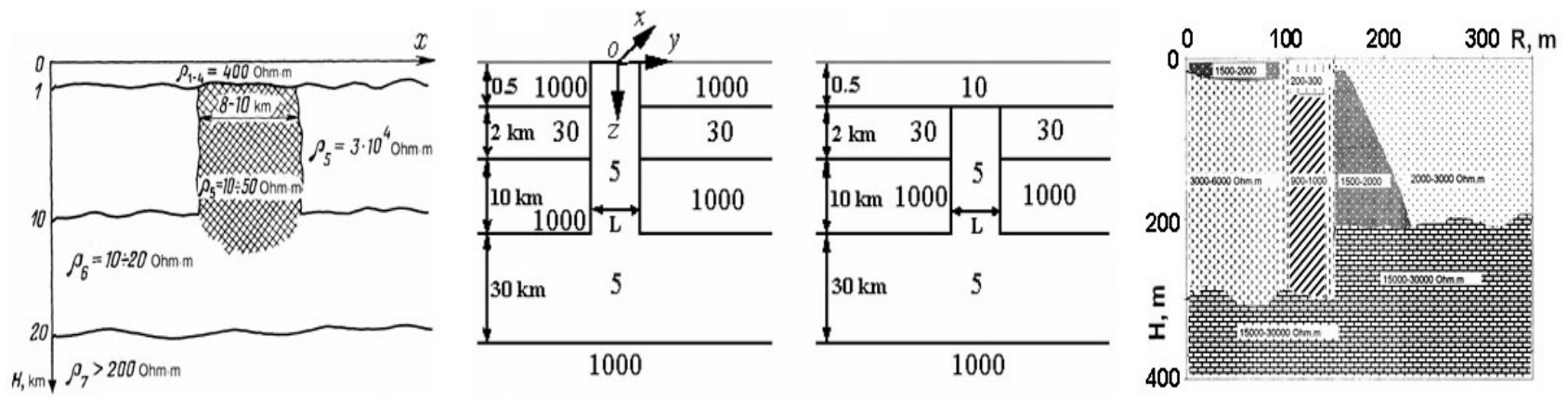

Figure 7. Geoelectric sections of faults of the Muyakan rift hollow (a) [29], Kamchatka peninsula (b,c) [19] and Baikal rift zone (d). Models: a), c) - closed faults; b) - deep conducting fault that overflows on the surface; d) - crushing zone of the upper part of the fault 


\section{Discussion}

Displacement currents exceed conductivity currents when $\rho=10^{4} \mathrm{Ohm} \cdot \mathrm{m}$ and $\varepsilon=10$ that is accepted in calculations for crystal rocks on frequencies already more that $180 \mathrm{kHz}$. This means that for low conducting crystal rocks in VLF-MF ranges it is necessary to define the geoelectric section according to dielectric permeability, as well. Numerical calculations of real geoelectric sections with different values of $\varepsilon$ confirm this fact. These calculations reflect essential dependence of electromagnetic field from $\varepsilon$ on frequencies of VLF-LF ranges.

Field measurements of dielectric permeability in the Baikal rift zone show that $\varepsilon=4.5-12$ for dry sandy sediments, $\varepsilon=20-40$ for humid clays, loams and peat bogs, $\varepsilon=7-20$ for crystal monolith rocks. Obtained data well conform to data on other regions and laboratory measurements on samples of rocks. Thus, crystal massifs in ELF-VLF-LF-MF ranges of electromagnetic waves should be considered as a semi-conducting or dielectric media. It is offered to give layered characteristics of dielectric permeability $\varepsilon$ of the geoelectric section for electromagnetic calculations within areas of prevalence of crystal massifs.

The Earth crust is divided by deep faults (crustal breach) into separate blocks with a form similar to rectangles. The width of zones of deep faults is equal to units-tens kilometers; the length is equal to hundred kilometers. Tectonic breaches are represented on the Earth surface by zones with large quantity of joints of different characters (zones of crush). Let us consider the geoelectric models of tectonic breaches (faults). Fig. 7a shows geoelectric section of tectonic relaxed conducting zone of fault of seismoactive Muya rift hollow [29]. The upper part of the sub-horizontal layered section $\rho_{1}-\rho_{4}$ is created by Cenozoic loose depositions with the thickness of 150-300 meters with the resistivity within hundreds $\mathrm{Ohm} \cdot \mathrm{m}$. The second geoelectric horizon is in the form of monolith rocks with the thickness of about 9-10 kilometers with the resistivity of $3 \cdot 10^{4} \mathrm{Ohm} \cdot \mathrm{m}$. Tectonic relaxed zone has a low resistivity within $10-50 \mathrm{Ohm} \cdot \mathrm{m}$ and the width of 8-10 kilometers. Intracrustal conducting layer $\rho_{6}$ with the thickness of 10 kilometers has the resistivity of $10-20 \mathrm{Ohm} \cdot \mathrm{m}$. We pay attention that the fault has a large width $(8-10 \mathrm{~km})$ and that there is a big contrast between resistivities of monolith rocks $\left(3 \cdot 10^{4} \mathrm{Ohm} \cdot \mathrm{m}\right)$ and fault zone (10-50 Ohm·m). Figs. 7 b,c,d show analogous geoelectric models of deep conducting faults of Kamchatka [19] and surface part of the Earth crust of the Baikal rift zone. Fault zones are registered on sounding data of $\rho_{\sim}$ in the VLF range from aircraft (Figure 6).

An original methodology of geoelectric mapping was created and substantiated separately for ELF and for VLF-LF-MF ranges in the Institute of Physical Materials Science of the Siberian Branch of the Russian Academy of Sciences [20]. GES maps of Eastern hemisphere of different scales (from 1:15000000 to 1:2500000) were created. These maps include also territories of the following countries: Turkey, Iran, Pakistan, Northern India, Afghanistan,
Mongolia, China, Korea, Japan and the eastern part of Russia. Such maps are necessary to calculate propagation and generation of electromagnetic fields of VLF-LF-MF ranges. Moreover they allow considerably to decrease errors of calculations of the attenuation function on real mountain-forest impedance radio-paths that are typical for seismoactive areas. Figure 8 shows map fragment of geoelectric sections parameters of Turkey.

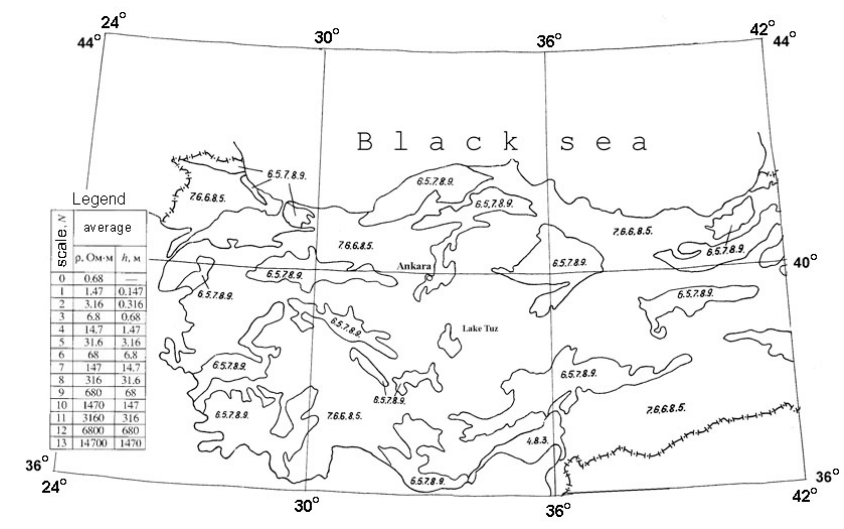

Figure 8. Geoelectric section map of Turkey (fragment) of 1:5000000 scale.
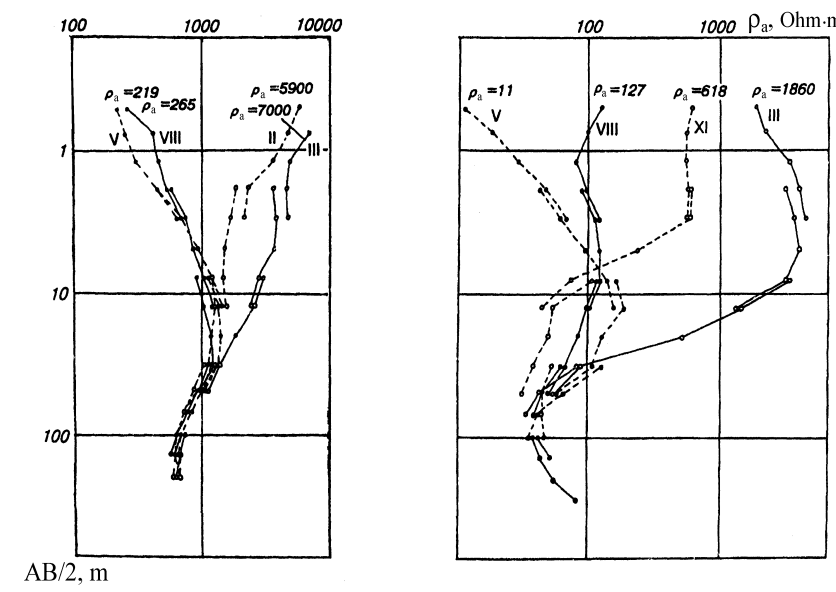

Figure 9. VES season curves on the south part of the Baikal rift zone: a) granitoids; b) - Quaternary sediments. Roman digits - months.

Previously, unknown appropriateness of seasonal changes of electrical properties of ground is revealed in conditions of rough continental climate and crylithozone. A model of temporal development of season modulation phenomena was worked out in GES parameters and in the electromagnetic field [20]. Figure 9 show seasonal curves of VES for granitoids and Quaternary sediments as illustrations. Seasonal variations of boundary surface impedance cause considerable variations of LF-MF electromagnetic field (Figure 10). The field increases 1.5-2.5 times more in winter than in summer. The physical reason of the detected strong seasonal variations of field is a seasonal change of GES parameters in the upper 10-25 meters of ground and change of electro-physics properties of the forest flora. It is suggested to create a cover map of electro-physics parameters of different types of forest media. 


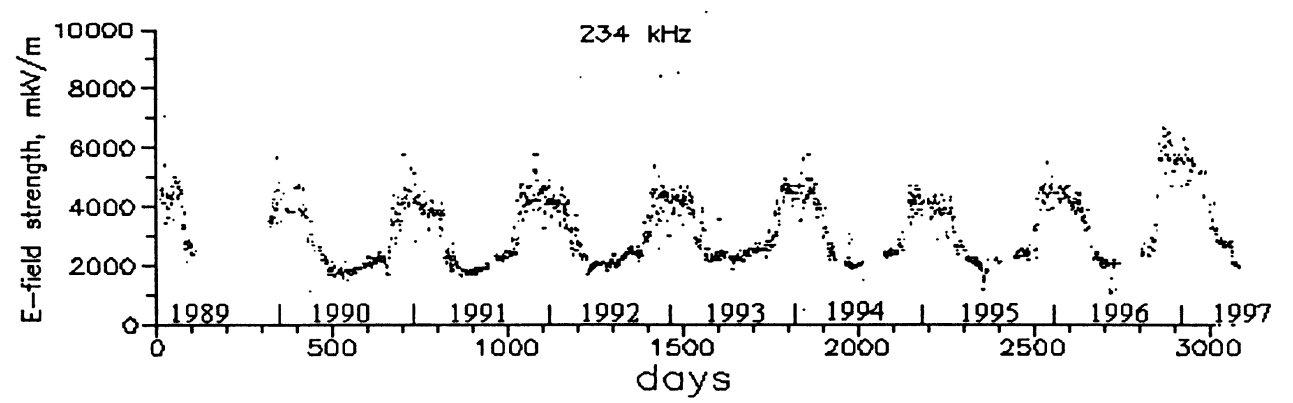

Figure 10. Season variations of electromagnetic field level on "Angarsk - Ulan-Ude" path

Permafrost rocks (cryolithozone) are widely presented in the regions with sub-polar and low-temperate climate (East Siberia, Alaska, Canada). Such rocks occupy about $24 \%$ of dry land. The layer thickness of permafrost rocks increases from south to north from a few meters to 1000 meters and more. The resistivity of the permafrost reaches $10^{4}-10^{6}$ $\mathrm{Ohm} \cdot \mathrm{m}$ on a direct current [23]. A considerable (in 3-10 times) frequency dispersion of electric conductivity of frozen loose sediments on $10-1000 \mathrm{kHz}$ is defined in comparison with a direct current when joint interpretation of results of radioimpedance sounding and VES was carried out. The frequency dispersion phenomenon was taken into account when the prognosis map of GES for permafrost zones was created [20]. It should be pointed out, that the monitoring of radon in the permafrost zone is not effective to forecast an earthquake because of big screening effect of layer of frozen loose rocks with the thickness up to 1000 meters.

Some problems on generation and propagation of seismogenic electromagnetic emissions are presented in works [7,11,24-32]. There the estimations of an attenuation of wide band emissions for homogeneous, discrete-layered and gradient media are given. Such estimations are necessary to calculate spatial-frequent and impulse characteristics of the natural filter that is a real geological medium. Let us consider a problem of propagation of the ground wave over an impedance radiopath that is over a fault zone.

Let a receiver of seismoactive emissions be situated in the middle of the fault zone. A source of emissions can have any azimuth in relation to the receiver and an axis of the fault. The path of electromagnetic wave propagation might: a) cross the fault axis; b) go along the fault axis; c) have an arbitrary angle to the fault axis. Concerning a Fresnel zone these situations will be as follows (Figure 11).

More complex two-dimensional situations can appear (Figure 11) when we take into consideration the finite fault length, the wave length, the path length and the availability of sections with other impedances.

The situation will be more complex if we enter into consideration mountain relief and wide band emissions (change of Fresnel zone size with $\lambda$ change). Just for these cases it is necessary to make calculations on the two-dimensional impedance radio-paths. The fault zone always has high conductivity relatively to around rocks $\left(\sigma_{\text {fault }}<<\sigma_{\text {around rocks }}\right)$. So an effect of "reconstruction" of the field of type "dry land - sea" takes place because of giving additional energy from the upper part of the propagation field to the bottom area (diffusion along wave fronts). Numerical calculations for a model path in the range of $2-1000 \mathrm{kHz}$ show a clear effect of "reconstruction" of the field within the fault area (Fig.12).

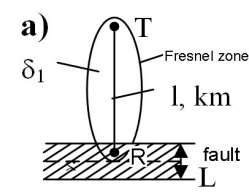
$\left|\delta_{1}\right|>>\left|\delta_{2}\right|$

d)

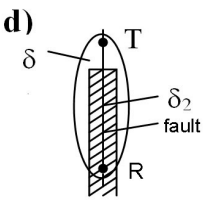

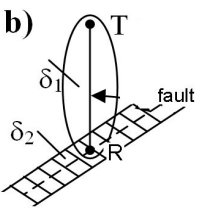

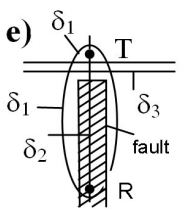

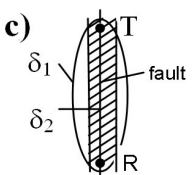

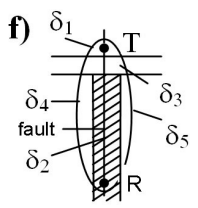

Figure 11. Some possible types of two-dimensional impedance radiopaths that are over fault zones; $\delta_{1}, \delta_{2} \ldots \delta_{5}$ - surface impedances of sections, T transmitter, $\mathrm{R}$ - receiver, $\mathrm{L}$ - fault width, 1 - radiopath length.

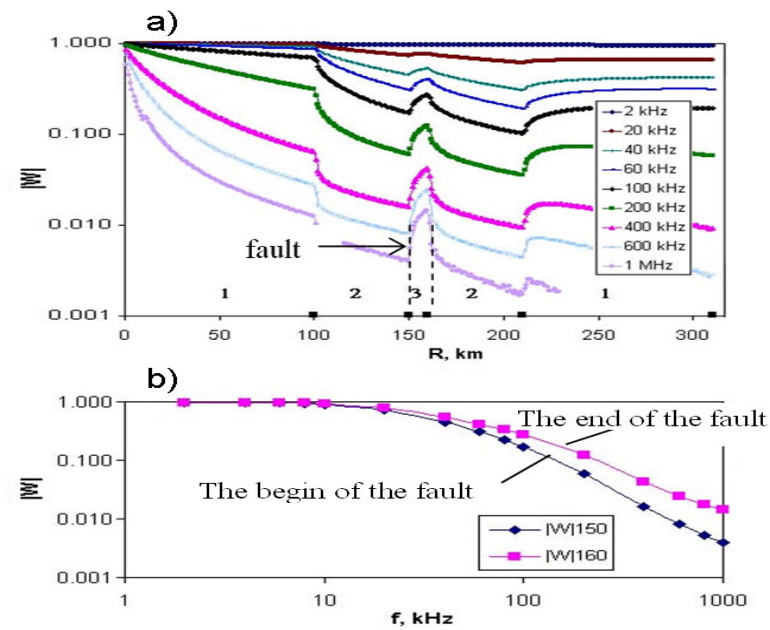

c)

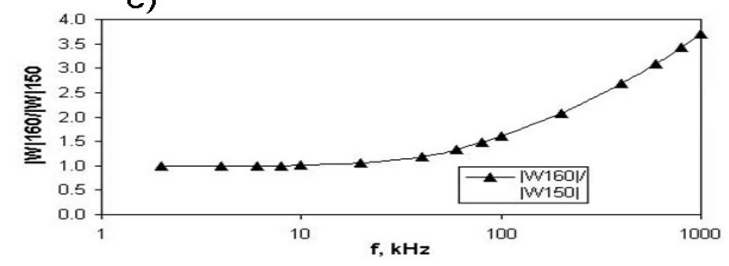

Figure 12 . a) Attenuation function module in the range of 2 - 1000 . $1-\rho=100 \mathrm{Ohm} \cdot \mathrm{m}, \varepsilon=20 ; 2-\rho=30000 \mathrm{Ohm} \cdot \mathrm{m}, \varepsilon=10 ; 3-\rho=1-50 \mathrm{Ohm} \cdot \mathrm{m}$, $\varepsilon=20$. b). Spectral characteristics of the impedance propagation channel on $\mathrm{R}=150$ and $160 \mathrm{~km}$. c) The frequency dependance of comparative field increase over the fault. 
The effect increases 3.8 times when frequency increases from 2 to $1000 \mathrm{kHz}$. In this time relative increasing of the field depends on the fault resistivity very faintly. Variations of $\rho$ within 1-50 $\mathrm{Ohm} \cdot \mathrm{m}$ do not change the ratio $|\mathrm{W}| 160 /|\mathrm{W}| 150$ and course of the spectral characteristics of the impedance channel. A higher level of the natural impulse electromagnetic field (NIEMF) observed within a row fault zones [31] is explained by influence of "landing" ground that has a high conductivity, and should not be explained by higher emission within fault zones.

\section{Conclusions}

Geoelectric sections (GES) of different types of the continental lithosphere (rift depression, crystal massifs, permafrost) up to the large depth are considered. A ground of models of lithosphere electric conductivities and seismoactive and seismostable regions are made. The main attention was given to areas of crystal massifs and geoelectric inhomogeneities zones (tectonic faults) that are related to seismic generating structures.

Detailed and sufficiently exact geoelectric models of lithosphere (maps and geoelectric sections) that are necessary for calculations of generation and propagation of seismogenic electromagnetic emissions have been worked out.

A commonness of creation of the Earth crust's inhomogeneities on electric and seismic indications and tectonic strain zones that are related to foci of earthquakes is considered. This commonness is connected with the character of metamorphic processes and, in the final analysis, with a geothermal regime of this or other structures.

It is defined, that hypocenters are concentrated as a rule not far from the boundaries between ledges of conducting bodies and high-resistive massifs. Contacts between blocks and bodies with contrasting geoelectric data should be considered as probable objects of a high seismic activity.

Our approach is based on the detailed study of geoelectrical construction of lithosphere of the seismo-dangerous region on depth and square. To define lithosphere "windows" and observe a channel of electromagnetic energy transmission is another approach.

The innovative character of the work is that for the first time main types of geoelectric structures in the seismoactive Baikal rift zone have been chosen and classified with the help of ground and remote (from aircraft) methods ELF-VLF-LF electromagnetic sounding and profiling. It is defined that the continent crust has considerable areas (up to hundreds of kilometers in length and in width) of a high resistivity $10^{4}-10^{6} \mathrm{Ohm} \cdot \mathrm{m}$ (lithosphere electromagnetic "windows").

Obtained experimental and theoretic results have been used for exploration of monitoring technology of the strain condition of Earth rocks.

Thus, the results of this study indicate the need to continue and deepen substantially initiated researches of seism electromagnetic and tectonic relationships in the Baikal rift zone, focusing them on the following tasks:

1. Organization of complex continuous geophysical monitoring of the system "lithosphere-atmosphere-ionosphe re-magnetosphere" on the basis of instrumental observations.

2. Investigation of interaction mechanisms of electromagnetic fields with rocks and crustal heterogeneities, particularly seismically active fault zones, radioimpedance and ground penetration radar (GPR) sensing methods.

3. Study seismoelectromagnetic emissions in the ULF VLF - LF bands on the Earth's surface and in the water of the Baikal Lake based on year-round observations.

\section{Acknowledgements}

This article was prepared with the partial financial support of RFBR, grant numbers 12-02-98002, 12-02-98007 and SB RAS integration project number 11.

\section{REFERENCES}

[1] M.Hayakawa (ed.): Electromagnetic phenomena Associated with Earthquakes. Published by Transworld Research Network, Kerala, India, 2009. 279 p.

[2] O.A. Molchanov., M. Hayakawa, Seismo-Electromagnetics and Related Phenomena: History and latest results, Terra Sci. Pub. Co. (TERRAPUB), Tokyo, Japan, 2008, 189 p.

[3] G.A.Zherebzov (ed.): Seismoionospheric and seismoelectro magnetic processes in the Baikal rift zone, Novosibirsk, Russia, Publishing House of the Siberian Branch of the Russian Academy of sciences, 2012, 304 p.

[4] Yu.B. Bashkuev, V.B. Haptanov, M.G.Dembelov, Radioprobing of underground structure of the Failure Gulf, formed as a result of the 7,5 Tsagan earthquake, Physics and Chemistry of the Earth, 2006, Vol.31, pp. 210-214

[5] Yu.B. Bashkuev, V.P. Melchinov, D.G .Buyanova et al., Cryosphere of the earth and its influence on electromagnetic processes in the seismoactive mountainous areas, Physics and Chemistry of the Earth, 2006, Vol.31, pp. 182-188.

[6] Yu.B. Bashkuev, I.B. Naguslaeva Yu. P. Malishkov et al., Electromagnetic "seismic calm" effect in the Baikal rift zone, Physics and Chemistry of the Earth, 2006, Vol.31, pp.336-340.

[7] M.Hayakawa and Y. Fujinawa. (ed.): Electromagnetic Phenomena Related to Earthquake Prediction, Terra Sci. Pub. Co. (TERRAPUB), Tokyo, Japan, 1994, 648 p.

[8] V.A.Tsarev, H.Sasaki, Low Frequency Seismogenic Electro magnetic Radiation: How Does It Propagate in the Earth's Crust and Where Can It Be Detected? , Atmospheric and Ionospheric Electromagnetic Phenomena Associated with Earthquakes, Ed. by M. Hayakawa, Terra Sci. Pub. Co. (TERRAPUB), Japan, Tokyo, 1999, pp. 383 - 393.

[9] Vanyan L.L., Elektromagnitnye zondirovanya, Nauchnyi mir, 
Moscow, Russia, 1997, 219 p.

[10] E.B.Fainberg, P.Andrie, M.N. Astapenko et. al., Glubinnye elektromagnitnye issledovaniya $\mathrm{v}$ Belorussii. Korovye zondirovania v ramkah proekta «Evroproba», Fizika Zemli, 1998, N 6, p. 53-63.

[11] E.V.Zvereva., A.M.Ryazantsev., I. N. Samuilov, D.N.Shakh suvarov, Izuchenie rasprostraneniya elektromagnitnyh voln $\mathrm{v}$ zemnoi kore, Rasprostranenie radiovoln, Nauka, Moscow, Russia, 1975, p. $312-354$.

[12] M.N.Berdichevsky, L.L.Vanyan., A.V.Koshurnikov, Magnit otelluricheskie zondirovaniya $\mathrm{v}$ Baikalskoi riftovoi zone, Fizika zemli, 1999, N 10, p. 3-25.

[13] Yu.A.Trapeznikov, E.V.Andreeva., V.Yu.Batalev et al., Magnitotelluricheskie zondirovania $\mathrm{v}$ gorah Kirgizskogo Tyan-Shanya, Fizika zemli, 1997, N 1, p. 3-20.

[14] I.G. Kissin., A.I. Puzaikin., Sootnoshenie mejdu seismoakti vnymi i elektroprovodyashimi zonami $\mathrm{v}$ zemnoi kore Kirgizskogo Tyan-Shanya, Fizika zemli, 1997, N 1, p. 67-76.

[15] I.G. Kissin., A.I. Puzaikin., Ochagi zemletryaseny v pole geoelektricheskih neodnorodnostey zemnoy kory Baikalskoy riftovoy zony, Fizika zemli, 2000, N 7, p. 21-29.

[16] A.A.Kovtun, Stroenie kory i verhnei mantii na severo-vostoke Evropeiskoi platformy (po dannym magnitotelluricheskih zondirovanii), Izd. Leningr. Univ., Leningrad, Russia, 1989, 284 p.

[17] Glubinnaya elektroprovodnost Baltiiskogo shita, Karelskii filial AN SSSR, Petrozavodsk, Russia,1986, 135 p.

[18] Geoelektricheskaya model tektonosfery Evraziiskogo skladc hatogo poyasa i sopredelhyh territorii. Pod red. V.V.Belyavskogo i S.N. Kumeka, Znannya, Kiev, USSR, $1998,264 \mathrm{p}$

[19] Yu. F. Moroz , Elektroprovodnost zemnoi kory i verhnej mantii Kamchatki, Nauka, Moscow, Russia, 1991, 182 p.

[20] Yu. B.Bashkuev, Elektricheskie svoistva prirodnyh sloistyh sred, Izd. SO RAN, Novosibirsk,Russia, 1996, 207 p.

[21] G.M. Morozova, M.I.Epov, Yu.A.Dashevsky,N.N.Nevedrov a., Elekrtoprovodnost zemnoi kory Baikalskogo prognosticheskogo poligona, Methods of study, structure and monitoring of the lithoshere, Materials of the International conferences, Izd. SO RAN, Novosibirsk, Russia, 1998, p. 251-253.

[22] Yu.B Bashkuev., V.B. Khaptanov, Ch. Ts.Tsydypov, D.G. Buyanova, Estestvennoe elektromagnitnoe pole v Zabaikalie, Nauka, Moscow, Russia, 1989, 112 p.

[23] V.M.Kalinin., V.S.Yakupov., Regionalniye zakonomernosti povedeniya moshnosti merzlyh tolsh, Yakyt. NC SO AN SSSR, Yakutsk, Russia, 1989, 144 p.

[24] O.A.Molchanov, M.Hayakawa and V.A.Rafalsky, Penetratio $\mathrm{n}$ Characteristics of Electromagnetic Emission From an underground seismic source into the atmosphere, ionosphere and magnetosphere, J.Geophys. Res., 1995, Vol.100, 1691-1712.

[25] A.V.Guglielmi, V.T.Levshenko, Elektromagnitnyi signal iz ochaga zemletryasenya, Fizika zemli, 1997, N 9, p. 22-30.

[26] V.V.Lasukov, Ozonnyi, perpolyatsionnyi i aerosolnyi mehanizmy elektromagnitnogo predvestnika zemletryaseniy a, Izv. VUZov. Fizika, 2000, N 2, p. 69-75.

[27] Elektromagnitnye predvestniki zemletryasenii, Nauka , Moscow, Russia, 1982, 88 p.

[28] V.T. Levshenko, Rezultaty i pespektivy issledovanii SNCH litosfernyh elektromagnitnyh signalov, Fizika zemli, 1998, N 11, p. 82-85.

[29] G.S.Vahromeev, A.Yu.Davydenko, Modelirovanie v razved ochnoi geofizike, Nedra, Moscow, Russia, 1987, 192 p.

[30] Yu.B. Bashkuev, V.B. Haptanov, The Method of Deep ELF Radioimpedance Sounding of Seismo-Active Regions, Atmospheric and Ionospheric Electromagnetic Phenomena Associated with Earthquakes, Ed. by M. Hayakawa, Terra Sci. Pub. Co. (TERRAPUB), Tokyo, Japan,1999, pp. 551-557.

[31] V.A.Liperovsky, O.A.Pokhotelov, S.D. Shalimov,Ionosferny e predvestniki zemletryasenii, Nauka, Moscow, Russia, 1992, $304 p$.

[32] B.S. Svetov, S.D. Karinsky, Yu.I. Kuksa V.I.Odintsov, Magnitotelluricheskii monitoring geodinamicheskih protsess ov, Fizika Zemli, 1997, N 5, p. 36-46. 